\title{
Endoscopic dacryocystorhinostomy: reasons for failure
}

\author{
Shay Keren $\mathbb{D}^{1} \cdot$ Avraham Abergel $^{2} \cdot$ Amir Manor $^{1} \cdot$ Amir Rosenblatt $^{1} \cdot$ Dvir Koenigstein $^{1}{ }^{1} \cdot$ Igal Leibovitch $^{1}$. \\ Ran Ben Cnaan'
}

Received: 2 October 2018 / Revised: 6 May 2019 / Accepted: 16 July 2019 / Published online: 8 October 2019

(c) The Author(s), under exclusive licence to The Royal College of Ophthalmologists 2019

\begin{abstract}
Objective Endoscopic dacryocystorhinostomy (DCR) is a widely performed and safe procedure for the treatment of nasolacrimal duct obstruction manifested as epiphora or dacryocystitis. Current success rates are above 90\%. Data on causes for failure of the procedure are sparse. We investigated the influence of several preoperative parameters on surgery outcome and to establish that parameters are linked with failure.

Methods A retrospective analysis of the medical records of all consecutive patients who underwent endoscopic DCR in the Tel-Aviv Medical Center, a tertiary referral center, between January 2010 and August 2016 were retrospectively examined and data on the occurrence of surgical failure and reasons for failure were retrieved.

Results A total of 165 patients (183 eyes) were included. The overall success rate for the surgery was $94.7 \%$. The parameters that correlated significantly with failure were coexisting diabetes mellitus $(P=0.037)$, allergy to medications $(P=0.034)$, and prior ocular surgery $(P=0.043)$. There was no correlation between the surgical failure rates and facial trauma, previous nasal or lacrimal surgery, or the usage of a stent.

Conclusion Endoscopic DCR is a safe and effective surgical procedure. Diabetes mellitus, allergies, and previous ocular surgery may lead to surgical failure. Patients with these risk factors should be aware of increased failure rates.
\end{abstract}

\section{Introduction}

Dacryocystorhinostomy is the preferred surgical solution for cases of nasolacrimal duct obstruction. The procedure involves the creation of an alternative pathway between the lacrimal sac and the nasal cavity, resulting in the bypass of the duct and allowing tears to be drained directly into the nasal cavity. This procedure was traditionally done by an external approach involving an incision on the nasal ridge, the creation of an opening in the lacrimal sac, the opening in the nasal bone (osteotomy) and mucosa, and the attachment of the lacrimal sac and mucosal openings to create the alternative pathway [1].

Endoscopic dacryocystorhinostomy (endo-DCR) was first described in the 1980 's, and has since gained popularity

Shay Keren

shaykeren88@gmail.com

1 Department of Ophthalmology, Tel-Aviv Medical Center Sackler School of Medicine, Tel-Aviv University, Tel-Aviv, Israel

2 Department of ENT, Tel-Aviv Medical Center Sackler School of Medicine, Tel-Aviv University, Tel-Aviv, Israel to become an alternative to the "gold standard" external DCR, and eventually being established as the preferred approach by many lacrimal surgeons. This approach allows a superior visualization of the lacrimal sac in comparison to the traditional external DCR, and allows the surgery to be completed with no cutaneous incision and with a better cosmetic outcome [2]. It also allows the concurrent handling of intranasal pathologies and abnormalities, such as deviated nasal septum, concha bullosa, or nasal polyps. The success rates of endo-DCR are comparable with those of external DCR, and are reported in the literature as being around $90 \%$ [3].

There are sparse articles on the reasons for failure of endo-DCRs. It has been suggested that failure may be attributed to inadequate surgical technique, resulting in a small osteum or incomplete sac marsupialization $[4,5]$. The development of granulation tissue and the level of experience of the surgeon were also associated with failure $[4,5]$. The objective of this study was to define predictors of endo-DCR failure by reviewing the relevant demographics, patient selection, and surgical techniques on a large cohort of patients in a single institution. 


\section{Patients and methods}

The medical records of all patients $(N=165)$ who underwent endo-DCR in the Tel-Aviv Medical Center, a tertiary hospital, between January 2010 and August 2016, were retrospectively examined. All patients presented with persistent epiphora and/or dacryocystitis events. All patients were examined by both an oculoplastic surgeon and an otorhinolaryngologist. Examinations included a complete ophthalmic assessment, syringing of the lacrimal system to verify obstruction, and an endonasal endoscopic evaluation of the nasal cavity. All the patients had an anatomical or presumed functional nasolacrimal duct obstruction. Those whose obstruction was proximal to the lacrimal sac, in the punctum or in the canaliculi were excluded.

The data extracted from the patients' files included demographic details, clinical characteristics, prior oculofacial trauma or surgery, prior lacrimal surgeries, findings on imaging studies, endo-DCR surgical technique, postsurgical care, treatment and outcome. The study was approved by the IRB committee of the medical center.

Surgical success was defined as symptomatic improvement with no further episodes of dacryocystitis and a patent rhinostomy evidenced endoscopically after the surgery. Failure was considered as anatomical if the rhinostomy osteum was closed and functional if the osteum was open but the epiphora symptoms persisted.

All the study patients had undergone powered endonasal endo-DCR under general anesthesia. The nasal mucosa was decongested with neuro patties soaked in a solution of $10 \mathrm{ml}$ tetracaine $3 \%$ and $1 \mathrm{mg}$ adrenalin. The lateral wall and maxilla of the middle turbinate were injected with $2 \%$ lidocaine and 1:100,000 adrenaline. All procedures were done with the use of a 0 or $30^{\circ} 4 \mathrm{~mm}$ nasal endoscope.

After elevating a posteriorly based mucosal flap using freer elevators, a bony window was created using a Kerrison punch for the frontal process of the maxilla and a diamond Barr for the upper part, ensuring complete exposure of the lacrimal sac. Once the lacrimal sac was fully exposed, a Bowman's probe was inserted through the upper or lower canaliculi, tenting the medial wall of the sac, which was then incised vertically along its entire length using an MVR blade. The medial wall of the lacrimal sac and the nasal mucosal flap were adjusted to cover exposed bone, based on patient's anatomy and osteotomy created, after which they were covered with a Gelfoam patch. A silicone stent (FCI 1400) was left in selected cases according to the surgeon's decision, mostly when there was canalicular stenosis, impaired anatomy, or a revision surgery. Intravenous broadspectrum antibiotics were used during surgery if any discharge had been detected in the sac.

Postoperatively, all patients were instructed to perform daily saline douching for 8 weeks. Cleaning and debridement of the surgical site were carried out at 2 weeks and follow-up was conducted routinely at $1,3,6,12,18$, and 24 months. Stents were removed between 3 and 6 months post surgery. Osteum potency was functionally evaluated by the use of fluorescein drops and anatomically evaluated by means of an endoscopic examination with or without irrigation at each visit.

\section{Statistical analysis}

Data were recorded in Microsoft Excel (2010) ${ }^{\mathrm{TM}}$ and analysed using SPSS version 23 (SPSS Inc., Chicago, IL, USA). Continuous variables, such as age, were compared between subjects using the independent sample t-test. For small group comparison, non-normally distributed and ordinal variables, Mann-Whitney non-parametric test was used. Binary variables were compared between subjects using Fisher's exact test or the Pearson chi-square test. Multivariate logistic regression was used to examine the independent effect of patient and clinical characteristics on surgical outcome. Variables were entered into the model if an association with a $P$ value of 0.15 or smaller was shown in the univariate analysis and no multi-colinearity was found between covariates. All tests were two tailed, and the threshold for statistical significance was defined as a $P$ value $<0.05$.

\section{Results}

A total of 165 patients (183 eyes) who were diagnosed as having nasolacrimal duct obstruction manifested as epiphora or dacryocystitis were included in the analysis. The mean age of the cohort was $53.9 \pm 18.6$ years (range 8-91), $129 / 183$ eyes were those of female patients $(70.5 \%)$. Surgery was conducted on the right eye in $98 / 183$ cases (53.5\%) and on the left eye in the remaining $85 / 183$ cases (46.5\%). The mean follow-up duration was 14.1 months. The study patients' characteristics are presented in Table 1.

Ocular pathologies were found in 20 eyes $(20 / 183$, $10.9 \%)$ and they consisted mostly of cataract $(n=4)$ or glaucoma $(n=8)$. Prior ocular surgery had been performed in 25 eyes $(25 / 183,13.7 \%)$, and it consisted mostly of cataract surgery $(n=14)$ or eyelid surgery, e.g., blepharoplasty or ptosis repair $(n=5)$. Nasal or sinus pathology was diagnosed in 25 eyes $(25 / 183,13.7 \%)$ and consisted mostly of a deviated nasal septum $(n=14)$ or polyps resulting from chronic sinusitis $(n=3)$. All patients were diagnosed as having epiphora for a duration of around 33 months or discharge for a duration of around 20 months.

172 of the 183 eyes $(93.9 \%)$ presented with an anatomical rather than a functional obstruction. Only $75(75 / 183,41 \%)$ underwent imaging studies (computerized tomography/ 
Table 1 Patients' characteristics

\begin{tabular}{|c|c|c|}
\hline Variable & No./Total & $\%$ \\
\hline Age (years) & $53.97 \pm 18.6$ & \\
\hline \multicolumn{3}{|l|}{ Gender } \\
\hline Male & $54 / 183$ & 29.5 \\
\hline Female & $129 / 183$ & 70.5 \\
\hline Hypertension & $47 / 183$ & 25.7 \\
\hline Diabetes mellitus & $24 / 183$ & 13.1 \\
\hline Ocular pathology & $20 / 183$ & 10.9 \\
\hline Allergies to medications & $16 / 183$ & 8.7 \\
\hline Prior ocular surgery & $25 / 183$ & 13.7 \\
\hline Previous punctoplasty & $27 / 183$ & 14.8 \\
\hline Previous dacryocystorhinostomy & $27 / 183$ & 14.8 \\
\hline Nose/sinus pathology & $27 / 183$ & 14.8 \\
\hline Facial trauma & $16 / 183$ & 8.7 \\
\hline Usage of chronic ocular medication & $5 / 183$ & 2.7 \\
\hline Usage of systemic medication & $65 / 183$ & 35.5 \\
\hline Number of dacryocystitis events & $73 / 183$ & 39.9 \\
\hline Nose cavity abnormalities & $58 / 183$ & 31.7 \\
\hline \multicolumn{3}{|l|}{ Type of obstruction } \\
\hline Anatomical & $172 / 183$ & 93.9 \\
\hline Functional & $11 / 183$ & 6.1 \\
\hline NLD imaging & $9 / 183$ & 4.9 \\
\hline Facial imaging (CT/MRI) & $75 / 183$ & 41.0 \\
\hline \multicolumn{3}{|l|}{ Side } \\
\hline Right & $98 / 183$ & 53.5 \\
\hline Left & $85 / 183$ & 46.5 \\
\hline \multicolumn{3}{|l|}{ Peri-surgical finding } \\
\hline Large dilated lacrimal sac & $61 / 183$ & 33.3 \\
\hline Small fibrotic sac & $27 / 183$ & 14.8 \\
\hline Output obstruction & $31 / 183$ & 16.9 \\
\hline Use of silicone tube & $105 / 183$ & 57.4 \\
\hline Biopsy & $12 / 183$ & 6.6 \\
\hline Follow-up (months) & $14.1 \pm 15.8$ & \\
\hline Post-surgical osteum granulation/adhesion & 19 & 10.4 \\
\hline Second surgery & 19 & 10.4 \\
\hline Overall success & $173 / 183$ & 94.7 \\
\hline
\end{tabular}

$N L D$ nasolacrimal duct, $C T$ computerized tomography, $M R I$ magnetic resonance imaging

magnetic resonance imaging) which showed dilatation or narrowing of the lacrimal duct in $12(12 / 75,16 \%)$, cystic enlargement of the lacrimal sac in $18(18 / 75,24 \%)$, or nasal mucosa hypertrophy in $18(18 / 75,24 \%)$. The most frequent intra-operative finding was a large dilated lacrimal sac due to the obstruction downstream $(n=61,33.3 \%)$.

The success rate for the entire cohort for the initial surgery was $83.1 \%$. The mean time to re-operation was 6.9 months in the failure group $(n=19,10.4 \%)$. At the second surgery, all the patients had adhesions, granulations
Table 2 Difference in failure rates between patients who were and were not affected by selected variables

\begin{tabular}{llll}
\cline { 1 - 2 } Variable & \multicolumn{2}{l}{$\begin{array}{l}\text { \% failure } \\
\text { value }\end{array}$} & \\
\cline { 2 - 3 } & $\begin{array}{l}\text { Not } \\
\text { affected }\end{array}$ & Affected & \\
\hline Age & 54.39 & 51.87 & 0.492 \\
& (years) & (years) & \\
Gender & & & 0.4 \\
Male & 81.4 & 18.6 & \\
Female & 87 & 13.0 & \\
Hypertension & 16.2 & 19.1 & 0.655 \\
Diabetes mellitus & 14.5 & 33.3 & 0.037 \\
Ocular pathology & 16.0 & 25.0 & 0.344 \\
Allergy to medications & 15.1 & 37.5 & 0.034 \\
Prior ocular surgery & 14.6 & 32.0 & 0.043 \\
Previous punctoplasty & 16.7 & 18.5 & 0.784 \\
Previous dacryocystorhinostomy & 15.4 & 25.9 & 0.176 \\
Nose/sinus pathology & 17.9 & 11.1 & 0.579 \\
Prior nose/sinus surgery & 17.6 & 14.6 & 0.814 \\
Facial trauma & 16.2 & 25.0 & 0.482 \\
Ocular medications & 16.3 & 40.0 & 0.2 \\
Systemic medication & 16.9 & 16.9 & 1.00 \\
Dacryocystitis events & 16.4 & 17.9 & 0.815 \\
Type of obstruction (functional/ & 16.3 & 9.1 & 1.00 \\
anatomical) & & & \\
Silicone intubation & 16.7 & 17.1 & 0.456 \\
Large dilated sac & 17.4 & 16.4 & 1.00 \\
Small fibrotic sac & 16.7 & 18.5 & 0.784 \\
Output obstruction & 18.6 & 7.4 & 0.609 \\
Biopsy & 18.1 & 0.0 & 0.224 \\
Post-surgical granulation/ & 10.0 & 68.4 & $<0.001$ \\
adhesion & & & \\
\hline
\end{tabular}

or fibrosis, and all but 2 patients (89\%) were left with a silicone tube. The overall final success rate was $94.7 \%$. Only one patient had a third operation.

The comparison between failure rates between the group of patients exposed to a specific variable and the group with no exposure is shown in Table 2. Only diabetes mellitus (DM) $(P=0.037)$, allergies to medications $(P=$ $0.034)$, and prior ocular surgery $(P=0.043)$ were found to be risk factors for surgical failure. A multivariable analysis showed a significance of 0.035 for DM and 0.030 for allergies. The postoperative finding of granulations or adhesions in the osteotomy site also correlated with surgical failure $(P<0.001)$. Other factors affecting facial anatomy and patent lacrimal ducts, such as facial trauma, prior nasal surgery, and concurrent nasal pathology, were not risk factors for surgical failure. Dacryocystitis was also not related to surgical failure, even in cases of multiple recurrences. 
The use of silicone tubing was not correlated with either success or failure of surgery $(P=0.456)$. There was no correlation between the use of a silicone tube and postoperative granulation formation $(P=0.456)$, while the presence of DM was highly correlated to postoperative granulation formation $(P=0.04)$.

\section{Discussion}

We describe a large cohort of patients who underwent endoDCR in a tertiary institute. We examined various preoperative and operative parameters that might influence the surgical outcome in order to identify reasons for failure and to improve patient selection. Jung et al. studied the outcome of 1083 endo-DCR surgeries and reported that age, sex, early tube removal, and indication for surgery were not correlated with higher failure rates [4]. The previous use of radioactive iodine, however, was connected to higher failure rates as was previous facial trauma, which was presented in $1.7 \%$ of their cases.

Age and sex were not related to surgical failure, nor were trauma or nasal cavity abnormalities, such as deviated nasal septum and prior nasal surgery, the parameters affecting nasal anatomy and believed to be connected to postoperative osteum potency. However, the number of patients in the trauma subgroup $(n=16,8.6 \%)$ was too small to reach any firm conclusions, and further investigation of their influence is warranted in a larger cohort.

Anatomical naso-lacrimal duct obstruction (NLDO) was defined in our study as symptomatic epiphora or dacryocystitis in the presence of reflux upon syringing. Functional NLDO was defined by us as symptomatic epiphora with a positive dye disappearance test, no spontaneous fluoresceine in the inferior meatus, no detectable cause, such as eyelid malposition, and in the presence of patent lacrimal drainage in syringing with no reflux. Dacryoscintillography is not routinely used to verify functional obstruction, and it was performed on only 10 of the patients in this study. We found no correlation between the type of obstruction and surgical outcome. Since the functional group in our study was small $(n=11)$, a study with larger numbers of suitable patients would be needed to shed more light on the relation between type of obstruction and surgical outcome. Wormald and Tsirbas prospectively investigated patients with functional obstruction, proven in dacrycystography and scintillography and found the endo-DCR has lower success rates (84\%) than patients with anatomical obstruction (97\%) [6].

There are no definitive guidelines for the application of silicone intubation during surgery, and it is usually left to the discretion of the surgeon. In recent years, we do not leave silicone tubes in the end of surgery routinely, unless the surgeon feels it is necessary. The use of silicone intubation did not affect the surgical outcome in the current series. Being as it is a foreign body, the tube was believed to increase the rates of granulation formation [7]: our results showed no correlation between the two. Fayers and Dolman found in a randomized controlled study on 300 patient who underwent non-endoscopic endonasal DCR, that the success rate, defined as both functional and anatomical patency, was significantly larger among the group in which silicone stenting was placed for a duration of 3 months [8]. Jung et al. stated that early silicone tube removal did not result in higher rates of failure [4]. Ali et al. described 283 endoDCR surgeries in which $279(98.6 \%)$ received silicone stents, and the overall success rate (including redo surgeries) was $96.9 \%$ [9], an outcome similar to ours. Previous randomized control trials on the usage of silicone stenting, and one meta-analysis, found no correlation to surgical outcome [10-13]. A 2016 publication on silicone stenting in endo-DCR, with an 18-month follow-up, found no difference in terms of surgical success between patients that did and those who did not undergo stenting [11]. In contrast, others described tubing as being associated with a larger reduction in osteum size, more granulation formation, scar tissue formation, and turbinoseptal synechia [7]. We specifically sought a correlation between tubing and granulation formation and there was none in the current study $(P=$ 0.456).

Dacryocystitis is the result of NLDO, with the acute or chronic symptoms of rubor, edema, pain, swelling and discharge from the punctum. It is considered an indication for surgical intervention, usually after the infection has been treated with antibiotics, but also in the acute phase as well [14]. Recurrent infection or chronic dacryocystitis is believed to cause fibrosis, granulation and narrowing of the lacrimal sac, necessitating special considerations during surgery [11].

Rabina et al. showed that a history of previous dacryocystitis events in cases of external DCR did not affect outcome [15]. Sun et al. reported that the success rate for endo-DCR after recurrent events of dacryocystitis was $\sim 94 \%$, similar to the success rates cited in the literature [11]. Our literature search yielded no studies that compared success rates of endo-DCR with or without dacryocystitis, but there are some publications on endo-DCR in the setting of an acute dacryocystitis which showed favorable outcomes $[12,13]$.

We found no correlation between the occurrence of infection and surgical failure. It made no difference in surgical outcome whether the lacrimal sac as observed during surgery was small, large, fibrotic, or free of fibrosis.

DM was a significant cause of surgical failure. It predisposes to wound ulceration, impaired healing and chronicity. A hyperglycemic state impairs both fibroblasts 
and endothelial cell functions in the organization of a productive granulation tissue and in achieving proper vascularization of a wound. Chronic non-healing wounds are common among patients with DM due to the impaired blood flow, loss of pericytes, decreased vascular processes in the level of the cell $[16,17]$. DM among the current study patient was highly related to granulation and scar tissue formation at the osteotomy site disrupting the natural healing process of the osteotomy edges. Granulation itself was a risk factor for surgical failure due to obstruction of the osteotomy.

Allergies to medications were also a cause for failure. Again, our literature search failed to yield any publication on that subject, and the mechanism is not altogether clear.

Past ocular surgery was found to be a factor for failure. This finding may be attributed to the effect of prior use of ocular medication peri-operatively that may cause fibrosis and narrowing of the lacrimal system. Not many of our patients were using topical medications mainly because they were young. It is possible that in an older age group, the incidence and correlation will be even higher.

One limitation of this study is the small number of patients in several of the selected parameters, which might have prevented their actual influence from being demonstrated. Another is that we did not note the glycaemic levels of the patients with DM who underwent endo-DCR. We also acknowledge that the definition of functional obstruction is somewhat controversial and further studies in that matter with relevant imaging might shed more light. One strength of this study is the large cohort of patients who were operated by the same surgeons under the same conditions. Also, numerous variables, both pre- and perioperative, were examined as was the influence of each on surgical outcome, for what we believe to be the first time. Finally, our definition of success was stringent for both a patent osteotomy seen endoscopically and the complete resolution of all symptoms. This strict definition probably lowered the success rate, but it better represents the real-life situation.

\section{Conclusion}

Endoscopic DCR is a safe and effective surgical treatment with high success rates. Its success appears to be influenced by preoperative parameters, especially DM. The mechanism that causes failure among diabetic subjects is not entirely understood and further investigation is warranted. Other factors that might be considered as problematic for endo-DCR, such as prior nasal surgeries or facial trauma, did not affect outcome in the current series and these patients can probably be safely operated. Ocular, nasal, and systemic history taking are essential for better coordinating therapeutic expectations and better patient selection.

\section{Summary}

\section{What was known before}

- It is known from previous articles dealing with endoscopic DCR that age and gender are not risk factors for surgical failure.

\section{What this study adds}

- We found that surgical failure (anatomical or functional) is higher among people with diabetes mellitus, allergies and previous ocular surgeries.

- We also found that previous lacrimal surgery, nasal surgery or facial trauma do not lead to higher failure rates.

\section{Compliance with ethical standards}

Conflict of interest The authors declare that they have no conflict of interest.

Publisher's note Springer Nature remains neutral with regard to jurisdictional claims in published maps and institutional affiliations.

\section{References}

1. Gauba V. External versus endonasal dacryocystorhinostomy in a specialized lacrimal surgery center. Saudi J Ophthalmol. 2014;28:36-9. http://linkinghub.elsevier.com/ retrieve/pii/S1319453413001367

2. Strong E. Endoscopic dacryocystorhinostomy. Craniomaxillofacial Trauma Reconstr. 2013;06:067-74. http://www.ncbi. nlm.nih.gov/pubmed/24436740

3. Marcet MM, Kuk AKT, Phelps PO. Evidence-based review of surgical practices in endoscopic endonasal dacryocystorhinostomy for primary acquired nasolacrimal duct obstruction and other new indications. Curr Opin Ophthalmol. 2014;25:443-8. http:// content.wkhealth.com/linkback/openurl?sid=WKPTLP:landingpa ge\&an $=00055735-201409000-00014$

4. Jung S-K, Kim Y-C, Cho W-K, Paik J-S, Yang S-W. Surgical outcomes of endoscopic dacryocystorhinostomy: analysis of 1083 consecutive cases. Can J Ophthalmol. 2015;50:466-70. http:// linkinghub.elsevier.com/retrieve/pii/S0008418215003282

5. Ali MJ, Psaltis AJ, Murphy J, Wormald PJ. Outcomes in primary powered endoscopic dacryocystorhinostomy: comparison between experienced versus less experienced surgeons. Am J Rhinol Allergy. 2014;28:514-6. http://www.ingentaconnect.com/content/ 10.2500/ajra.2014.28.4096

6. Wormald PJ, Tsirbas A. Investigation and endoscopic treatment for functional and anatomical obstruction of the nasolacrimal duct system. Clin Otolaryngol Allied Sci. 2004;29:352-6. http://doi. wiley.com/10.1111/j.1365-2273.2004.00836.x. 
7. Longari F, Dehgani Mobaraki P, Ricci AL, Lapenna R, Cagini C, Ricci G. Endoscopic dacryocystorhinostomy with and without silicone intubation: 4 years retrospective study. Eur Arch OtoRhino-Laryngol. 2016;273:2079-84. http://link.springer.com/10. 1007/s00405-015-3876-2

8. Fayers T, Dolman PJ. Bicanalicular silicone stents in endonasal dacryocystorhinostomy. Ophthalmology. 2016;123(Oct):2255-9. http://www.ncbi.nlm.nih.gov/pubmed/27432206

9. Ali MJ, Psaltis AJ, Murphy J, Wormald PJ. Powered endoscopic dacryocystorhinostomy: a decade of experience. Ophthal Plast Reconstr Surg. 2015;31:219-21. http://content.wkhealth.com/ linkback/openurl?sid $=$ WKPTLP:landingpage $\& a n=00002341$ 201505000-00011

10. Knisely A, Harvey R, Sacks R. Long-term outcomes in endoscopic dacryocystorhinostomy. Curr Opin Otolaryngol Head Neck Surg. 2015. http://content.wkhealth.com/linkback/openurl?sid= WKPTLP:landingpage\&an $=00020840-900000000-99525$

11. Sun Y, Wang H, Wang Y, Yan Y, Gao Q, Di W, et al. Endonasal endoscopic treatment of recurrent dacryocystitis. Cell Biochem Biophys. 2013;67:1441-4. http://link.springer.com/10.1007/s12013013-9684-7

12. Madge SN, Chan W, Malhotra R, Ghabrial R, Floreani S, Wormald PJ, et al. Endoscopic dacryocystorhinostomy in acute dacryocystitis: a multicenter case series. Orbit. 2011;30:1-6. http://www.tandfonline.com/doi/full/10.3109/01676830.2010. 535952

13. Chisty N, Singh M, Ali MJ, Naik MN. Long-term outcomes of powered endoscopic dacryocystorhinostomy in acute dacryocystitis. Laryngoscope. 2016;126:551-3. http://doi.wiley.com/10. 1002/lary. 25380

14. Kamal S, Ali MJ, Pujari A, Naik MN. Primary powered endoscopic dacryocystorhinostomy in the setting of acute dacryocystitis and lacrimal abscess. Ophthal Plast Reconstr Surg. 2015;31:293-5. http://content.wkhealth.com/linkback/openurl?sid=WKPTLP:la ndingpage \&an $=00002341-201507000-00010$

15. Rabina G, Golan S, Neudorfer M, Leibovitch I. External dacryocystorhinostomy: characteristics and surgical outcomes in patients with and without previous dacryocystitis. J Ophthalmol. 2013;2013:1-4. http://www.hindawi.com/journals/ joph/2013/287524/

16. Berlanga-Acosta J, Schultz GS, López-Mola E, Guillen-Nieto G, García-Siverio M, Herrera-Martínez L. Glucose toxic effects on granulation tissue productive cells: the diabetics' impaired healing. Biomed Res Int. 2013;2013:1-15. http://www.hindawi.com/ journals/bmri/2013/256043/

17. Okonkwo UA, DiPietro LA. Diabetes and wound angiogenesis. Int J Mol Sci 2017;18:1419. http://www.mdpi.com/1422-0067/18/ $7 / 1419$ 